\title{
A CASE OF LATE HEREDITARY SYPHILIS OF THE NOSE, PHARYNX, AND LARYNX.
}

\author{
By Dr. Ricardo Botey, of Barcelona.
}

I BELIEVE the publication of this case of late hereditary syphilis to be interesting for two reasons ; first, because it gave rise to some difficulties of diagnosis for a period of three years; and, secondly, because of its rarity, if not for the syphilographer, at least for the rhino-laryngologist, and I believe that, in Spain at any rate, it is the first case of the kind which has hitherto been published.

Case : Andres Casas, fourteen years of age, apprenticed to a painter, suffered for three years and some months with his throat and nose. He is puny and thin for his age, not appearing to be more than ten or eleven years old. He first consulted me on the 13th October, $189 \mathrm{I}$, with very marked dyspnœea. The voice was excessively raucous and nasal, and respiration was very short, breathing through the nose being impossible. In spite of this, deglutition was easy and painless. There was sub-orbital neuralgia and nasal blennorrhoa. He said that three years before, in consequence of diphtheria of the throat, this latter had troubled him, at which time the larynx, and later, the nasal fossa had been affected.

Examination.-There was seen, ulceration and necrosis of the cartilaginous septum of the nose, necrosis of the floor of the nasal fossæ, with a sequestrum of the size of a small nut, and behind the second premolar destruction of the palatine vault with stellar cicatrices ; cicatrized ulceration of the epiglottis which was in part destroyed and deformed. The interior of the larynx was unrecognisable; filled with condylomatous vegetations, principally about the glottis and the entry to the ventricles of Morgagni. The ventricular bands were irregularly hypertrophied as if they were in part formed of granulation tissue. The larynx formed a sort of funnel, at the bottom of which was seen an irregular space through which air passed with a whistling sound and without its being possible to distinguish the vocal cords, which had apparently disappeared, or were hidden from sight by the great hypertrophy of the mucous membrane (Fig. I).

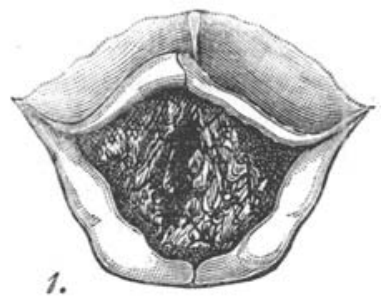

After a drewing by DR. R. Boter.

Cervica: adenopathy of the submaxillary and lateral glands of the neck also existed, and they were hard to the touch and of the size 
of small nuts. In spite of the difficulty of auscultation, I do not think there was anything abnormal in the heart or lungs.

Strongly suspecting syphilis, I interrogated the patient and his mother (who accompanied him) as to any previous morbid manifestations. The mother denied any syphilitic affection; she had nursed her child, and no one amongst her entourage had been affected with any venereal disease, and she herself had been quite free from such disorder. I, however, remarked that in questioning her she became suddenly red, and that she hesitated in her answers to some questions, besides being contradictory in some of her statements. I, however, pretended not to doubt her. Some days afterwards she told me that she had aborted twice, that her husband had a mistress, and that he frequented the company of prostitutes, and that he had had crusts on the hand and taches on the body two years before the birth of this child ; moreover, that she had had an eruption on the body a year before her confinement, to which she attached no importance, and which resembled, as she expressed it, an abortive measles. A few weeks after this she lost much hair, and she had pains in the limbs, especially in the tibiæ, which pains were worse at night-time. I begged her to bring her husband one day. He came and I questioned him. He confessed that he had had syphilis, and that his physician (Dr. Sanchez) had treated his wife for this disease, and that he had communicated the disease to her, begging me also not to enlighten her as she was ignorant of the fact.

I was satisfied that syphilis in the parents was clearly established.

Dr. Alabert, the doctor of the family, informed me that this child was born at full term, but was weakly and thin, and he commenced to walk only at the age of sixteen months. His growth was slow, and he was more delicate and smaller than other children of that age. No manifestation of the diathesis occurred during the first few weeks of life. There was no keratitis and no disease of the ears, the only thing being a small exostosis on the left tibia at the age of seven. At ten, when at Reno, in the province of Tarragona, he had diphtheria; a few weeks after the voice became nasal, and he regurgitated food through the nose. His voice subsequently became so hoarse that he was completely aphonic. Nasal respiration became difficult, he had a discharge of pus, and eliminated two small fragments of bone when blowing the nose, but did not exhibit any other symptoms.

Respiration became gradually shorter and shorter, until distinct stridor appeared, due to stenosis of the larynx. He was then treated by various physicians, who diagnosed the disease as tuberculosis, scrofula, chronic laryngitis, etc.

I made the patient undress, but I found only the small tibial exostosis. The teeth, however, were affected in a manner which deserves notice. There was no notching of the incisors (Hutchinson), but punctiform erosions on nearly all the teeth, which were without enamel. There was also slight atrophy of the crowns of the two lower first molars, and amorphism of the canines, which appeared like small incisors.

1 instituted energetic anti-syphilitic treatment, and at the end of fifteen days the larynx had the appearance (depicted in Fig. 2)-i.e., the 
lumen of the glottis had enlarged considerably, causing the stridor, which endangered life, to disappear, and permitting a view of a small portion of the left vocal cord (Fig. 2). The patient took three grammes of iodide of potassium a day, and had daily frictions of the armpits and thighs, with ten grammes of mercurial ointment. He was freely salivated, with enlargement of the tongue. Frictions were discontinued, and he then took only two grammes of iodide. As soon as the specific stomatitis disappeared I put him on to "Sirop de Gibert," and made erdo-laryngeal applications of bichloride, one per cent. every other day. His condition improved greatly, his respiration became free, and the voice was no longer aphonic, but merely hoarse. I then removed a small sequestrum from the nasal septum, and that from the palatine vault, which came away

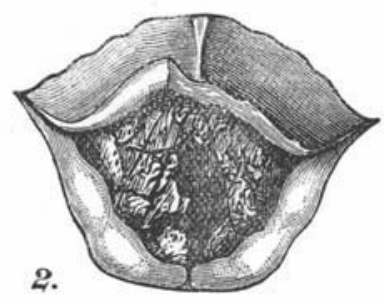

After a drawing by DR. R. BOTEY.

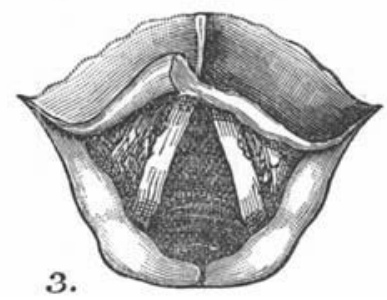

After a drawing by DR. R. BoTEY.

easily, with very little traction. In spite of this $I$ believed that in the end I should have to eliminate the laryngeal condylomata, for I did not think they would disappear by this treatment alone, and I feared that ultimately, perhaps, the cicatricial retraction would lead to fibrous stenosis of the glottis, and I imagined would require Schroetter's tubes later on. But nothing of this kind occurred. Little by little the laryngeal vegetations disappeared, the epiglottic ulceration cicatrized completely. Respiration was fairly established through the nose, but a large oval perforation of the cartilaginous septum was left. The ventricular bands commenced to define their contours little by little, but were left somewhat irregular in form. And below this mass of granulations and newly-formed tissue appeared two vocal cords, perfectly smooth on their edges, but still a little red and swollen (Fig. 3). At the end of three months of energetic antispecific treatment, accompanied with local applications of bichloride of mercury, the larynx of the patient appeared to be almost normal, leaving practically only the destruction of the fore-edge of the epiglottis on the left side (Fig. 3), and small irregular nodosities on the ventricular bands. Voice became normal and respiration absolutely free, the vocal cords later resumed their white pearly appearance, and the patient was then cured.

I have reproduced the pictures of the larynx in order to demonstrate the power of specific treatment in tertiary syphilis of this organ in children and adolescents. The result would certainly not have been the same in the adult, or even in many such cases, for we cannot deny that the most energetic specific treatment has very often only a feeble effect upon tertiary non-ulcerative syphilis of the larynx. This treatment undoubtedly cures, but there remains something of the local lesion, especially when it 
is neo-formative, as in this case, which disappears only under treatment with cutting forceps, the galvano-cautery or Schroetter's bougie. Even in these cases we obtain only partial disappearance of the local lesion, for we remove only the portions of the newly-formed tissues which interfere with phonation or respiration, and cicatricial contraction requires dilatation of the orifice of the glottis, for it is well known that neither mercury nor iodide can have any action upon the new tissue, which causes the terrible syphilitic stenosis of the larynx and trachea.

Mauriac has rightly said, " "Neoplasia of tertiary laryngopathies, what" ever their form, extent, and localization, are almost never spontaneously " resolved. They end in destruction of the tissues by necrobiosis, or their "transformation into fibrous tissue."..."Laryngeal stenosis is the con" sequence of these two processes. It varies between wide limits, but in " all its degrees it compromises more or less completely the functions of " respiration and at the same time that of the voice. If it is often arrested " and ends not in extreme consequences it scarcely ever retrogrades, "whatever one may do to cause its disappearance."

Consequently, in spite of the fact that there perhaps exists an acute laryngo-stenosis, by infiltration of the larynx, progressive narrowing of the larynx, by cicatrix or sclerosis of numerous laryngeal neoplasia, i.e., sloz and definite laryngo-stenosis, is not established. The new-formed tissue is reabsorbed, disappears and leaves scarcely any traces.

These lesions were, moreover, limited exclusively to the larynx; the trachea and bronchi were indemnified ; at least, I could not observe any symptom pointing to their implication or even giving a suspicion of such.

The case was therefore one of tertiary laryngopathy, with equivocal appearances, benign, and with an insidious and quick course. In such a case the respiratory troubles are produced slowly, and increase only little by little, so that the patient's attention was only gradually drawn to these symptoms, like that of the doctors who attended him at first. It was only later on that they became grave, so that one of the physicians who treated him last proposed tracheotomy as the only means of averting death, which he advised must quickly occur.

And yet all, or nearly all, disappeared, as can be seen by comparing the first figure with the third, solely by anti-specific treatment.

This fact, the truth of which I cannot doubt, since I have had the patient under observation for four months, raises an objection to the general rule, which, as I have already said, is that tertiary syphilitic neoplasms of the larynx are always refractory to all treatment, i.e., that their retrogression cannot be relied upon, in spite of the most energetic and prolonged treatment.

The age of the child (fourteen years) and the possibly very embryonic constitution of the laryngeal neo-formations were probably the two conditions which led to this brilliant and unexpected result, almost without any local intervention. The case is further notable from the fact that it is very rare to find associated grave pharyngo-nasal syphilis with laryngeal syphilis, and if it has been rightly said that syphilitic lesions of this part have a great tendency to descend, this is only true for the larynx.

I Charles Mauriac, "Syphilose du Larynx de la Trachée et des Bronches." Assetin et Houzeau, Paris, 1890, p. 6. 